\title{
Wilderness Values in America: Does Immigrant Status or Ethnicity Matter?
}

\author{
CASSANDRA Y. JOHNSON \\ J. M. BOWKER \\ Southern Research Station \\ USDA Forest Service \\ Athens, Georgia, USA \\ JOHN C. BERGSTROM \\ Department of Agricultural and Applied Economics \\ University of Georgia \\ Athens, Georgia, USA

\section{H. KEN CORDELL} \\ Southern Research Station \\ USDA Forest Service \\ Athens, Georgia, USA
}

\begin{abstract}
Little is known about the values immigrant groups or U.S.-born racial and ethnic minorities attribute to wilderness. However, the views of these groups are important to wilderness preservation because of increasing diversity along ethnic, cultural, and racial lines in the United States. We examine the proposition that wilderness is a social construction (valued primarily by U.S.-born Whites) by comparing wilderness values for immigrants and U.S.-born minority respondents to Whites. Results from 10 wilderness value items show immigrants are significantly less likely to indicate on-site use value. Among U.S.-born racial/ethnic groups, Black respondents were least likely to indicate values associated with visitation and off-site use but as likely as Whites to indicate a value for continued existence of wilderness. U.S.-born Asians and Latinos were also less likely than Whites to indicate values relating to wilderness on-site use. Implications of findings for wilderness as social construction are discussed.
\end{abstract}

Keywords environmental perception, immigrants, race/ethnicity, wilderness value

At the annual meeting of The Wilderness Society in 2000, a panel of wilderness advocates, researchers, and other constituencies considered the question: "Is wilderness in its statutory or historically advocated form relevant for the expanding

Received 16 January 2003; accepted 19 March 2004.

Address correspondence to Cassandra Y. Johnson, USDA Forest Service, Southern Research Station, 320 Green Street, Athens, GA 30602, USA. E-mail: cjohnson09@fs.fed.us 
demographic diversity of the United States?" As the question suggests, the demographic changes that have occurred in recent decades and those expected over the next half century may impact natural resource use and management profoundly. We consider and address this question with national survey data gathered on wilderness values. We examine variation in wilderness value indicators for immigrants and those born in the United States, as well as variation by race and ethnicity for nativeborn respondents.

The U.S. population is expected to increase substantially over the next 50 years, ${ }^{1}$ with an increase of $50 \%$ over 1995 population levels (U.S. Department of Commerce 1996). Immigration and the relatively higher fertility rates of the largest immigrant groups (Latinos and Asians) will contribute most significantly to total population growth in coming decades (U.S. Department of Commerce 1996, 15; Castles and Miller 1998, 145). This rapid population increase has implications for the environment generally because of the inevitable increase in demand for natural resources (Ehrlich and Ehrlich 1990; Beck 1997; Pimentel, Giampietro, and Bukkens 1998; Cordell, Green, and Betz 2002). These increases are also important to consider for wilderness designation and management because, again, the resources required to sustain a growing population could compete for the land base available for wilderness (Schönfeld 2000).

In addition to considering resource depletion, it is also crucial to think about possible cultural and class biases associated with wilderness. Both the wilderness concept and its advocates have been criticized for being elitist (Cronon 1996; Callicott 1994/1995; Taylor 2000). Critics charge that wilderness reflects the interests of environmental enthusiasts who tend to be well educated, White, male, and in the middle to upper income classes (DeLuca 1999; Walker and Kiecolt 1995). Indeed, on-site studies of wilderness visitors show users typically fall within these categories (Roggenbuck 1988; Lucas 1989; Watson et al. 1992; Williams et al. 1992; Winter 1996). If wilderness and the values it represents are appreciated primarily by a relatively small, exclusive portion of the population, then the continued support of such political land designations may be less relevant to immigrant groups or to native-born ethnic and racial minorities because of class or culture differences (Callicott and Nelson 1998).

\section{Wilderness as Social Construction}

Because the contemporary wilderness concept was influenced to a great degree by ideals specific to American identity formation, the perception of wilderness and the values attributed to it have been described as cultural or social constructions. That is, the meanings and connotations associated with wilderness are not inherent or absolute, but rather any label assigned to wilderness necessarily reflects the subjectivity of the perceiver. It has been argued that wilderness is the creation of a given set of people at a particular point in time with particular cultural, social, and political interests (Cronon 1996; Greider and Garkovich 1994; DeLuca 1999; Williams 2000; Stankey 2000, 17). ${ }^{2}$

This is a compelling argument given the difficult histories various racial and ethnic minority groups have had with wildlands in this country (Schelhas 2002). ${ }^{3}$ According to its legal definition, wilderness is a place where one goes to escape the organization and noise of civilized society (Wilderness Act of 1964 [Public Law No. 88-577, 78 Stat. 890,890 , codified as amended at 16 USC 1131(c) (1994)]). Wilderness is prescribed by often-quoted nature advocates such as Henry David Thoreau and John Muir as the 
antidote for the self-alienation brought on by civilization. One retreats to the woods to renew, to touch base again with a necessary simplicity that sustains the spirit. The question for our research is whether immigrants or native-born ethnic minorities perceive of wilderness in such redemptive, idealistic terms; that is, do these ideas about wilderness extend to other cultures or ethnic and racial subgroups? For instance, do immigrants or ethnic minorities express values similar to those of native-born Whites concerning attitudes, preferences, and behavior related to wilderness?

\section{Non-Western Views of Wilderness}

Guha's (1989) critique of radical environmentalism provides insight into cultural and socioeconomic variations in wilderness perception. According to Guha, wilderness preservation for the sake of biotic communities can be disadvantageous for poor citizens in some Third World countries because traditional communities may be displaced by the designation of animal preserves. The designation of these areas in the Western sense of nonhuman habitation effectively transfers land rights from the peasantry to wealthy power agents.

Parajuli (2001) also writes that the nature/culture dichotomy so prevalent in Western conceptions of wilderness is unfamiliar in peasant societies throughout the world. For these "ecological ethnicities" (ethnic or other societal groups that practice sustainable forms of harvesting or resource extraction) in developing countries, there exist no discrete units of territory called wilderness contrasted with places where people dwell. Western (2001) raises similar concerns about wild game preserves in Africa, arguing that the idea is foreign to native groups. Southgate and Clark (1993) charge that wilderness preserves in South America also displace indigenous people.

Inglehart's (1990) postmaterialist thesis offers a socioeconomic explanation for examining Western and non-Western conceptions of wilderness. According to Inglehart $(1990 ; 1995)$, the emergence of scarcity-free, postmaterial societies in the last half of the 20th century allows individuals in those societies to adopt more egalitarian attitudes and express interests more inclusive of others in society. Because material needs of many in Western or industrialized nations are satisfied, more Westerners are freer to concentrate on issues and concerns besides their most fundamental, such as racial and gender equality, animal rights, and environmental protection, including wilderness preservation. ${ }^{4} \mathrm{Nash}$ (1982) refers to this as the "'full stomach' phenomenon." Again, because the bulk of recent U.S. immigration stems from less developed nations that have yet to realize postmaterialist conditions on a par with advanced, industrialized countries, Inglehart $(1990 ; 1995)$ would predict that recent immigrants would be less attuned to Western conceptions of wilderness than native-born Americans (Altieri and Masera 1993).

Recent studies indicate that for some environmental activities, immigrants actually display more proenvironmental behavior than native-born Americans. Hunter (2000) found that immigrants expressed a greater degree of environmental concern for hazards and greater frequency in modifying their behavior to be more environmentally sensitive. Pfeffer and Stycos's (2002) comparison of native and immigrant environmental behavior in New York City showed immigrants were more likely to say they conserved water. These findings would suggest that concerns about immigrants contributing to environmental degradation may be unwarranted. Whether such environmental concern extends to wilderness is an empirical question, as wilderness preservation may be more esoteric than other environmental issues. 


\section{Native-Born Racial/Ethnic Variation in Wilderness Interaction}

Existing research shows U.S.-born African Americans are less likely than Whites to visit wilderness or to engage in wildland-related recreation activities, with the exception being fishing (Johnson et al. 2000; Gramann 1996; Washburne 1978). However, data from the National Survey on Recreation and the Environment showed Blacks reported similar or higher concern levels for benefits associated with wilderness, compared to Whites (Johnson et al. 2000). The reasons for differences in Black/White wilderness concern and use have not been fully explored, although data from the same national study showed Blacks were more likely than Whites to say they did not visit wilderness because of structural constraints such as travel-related expenses and lack of basic services in wilderness. Blacks were also more likely to cite internal constraints related to feelings of discomfort in the wild, desire for outdoor recreation places with more people, and concern for personal safety in the wild (Johnson et al. 2001b).

With respect to Latino Americans and wilderness, Lynch (1993) argues that Latino ontology differs from mainstream American environmentalism in that the former does not distinguish people from the landscape. This perspective is similar to the Third World critiques cited earlier. And again, this viewpoint is contrasted with the middle-American view of nature as separated from the individual and community.

The many ways in which various Asian cultures have penetrated American culture are widely reported in the popular press (Barker 2001). For instance, the emphasis on feng shui (the ancient Chinese art of environmental design, which stresses that one's well-being depends on how one's living space is arranged) by Chinese Americans suggests the importance of environment in East Asian culture. But little is known about how Asian American groups view wilderness.

Because of wilderness's culture-specific bases, we ask how pervasive are certain values associated with this resource. We acknowledge that neither immigrants nor native-born ethnic minorities are monolithic, and that we cannot address subcultural differences within immigrant groups because of data limitations. Wide variations exist in culture among immigrants, even among immigrants stemming from the same region of the world. Nevertheless, by examining immigrant and native-born $\mathrm{racial} / \mathrm{ethnic}$ minority responses to questions and statements about an array of wilderness behavior, attitudes, and preferences, we gain some indication of the values attached to these lands by these important constituent groups.

\section{Wilderness Values}

Value is defined as the worth of something to its possessor (Bannock, Baxter, and Davis 1998). Similarly, we describe wilderness values as the relative worth, utility, or importance attributed to the use or existence of wilderness preserves. A wilderness value is a latent construct. As such, it cannot be directly measured, but rather inferred by the measurement of a proxy or value indicator. Recent empirical work examining wilderness value indicators suggests Americans generally favor nonuse values $^{5}$ over use values (Cordell et al. 1998). Cordell and Stokes (2000) examined 13 wilderness value indicators. These indicators related to direct use of the resource; optional use, that is, valuing option to use wilderness in the future; nonuse wilderness existence; and bequest, valuing wilderness preservation for future generations. Results showed nonuse values implying protection of water, wildlife habitat, air, endangered species, and bequest values were rated highest by respondents. Similar 
results were found for Cordell, Tarrant, and Green's (2003) comparison of the same 13 wilderness values over time (1994-2000).

Cordell et al. (2003) found an increase in the percentage of respondents rating the 13 value items as extremely important over the 6-year period. However, the analysis did not control for a number of factors including race, ethnicity, or immigrant status.

To assess whether wilderness is a social construction valued primarily by nativeborn Whites, we examine the following broad questions:

1. Are immigrants less likely than U.S.-born respondents ${ }^{6}$ to value wilderness?

2. Are native-born racial/ethnic minorities (Blacks, Latinos, Asians) less likely than native-born Whites to value wilderness?

Because there is no simple measure or index of wilderness value, we operationalize our assessment of these broad questions by developing and modeling a number of indicator questions and statements over a large, national cross-sectional sample.

Gender, socioeconomic status, and age have also been shown to be correlated with wilderness perception and use, and it is likely that these variables interact with race and ethnicity to influence wilderness valuation. While these associations are acknowledged, we include gender, age, education, and other sociodemographic variables as control variables in our analyses. The focus of this article's analysis and discussion is the effects of immigrant status and race and ethnicity on wilderness values.

\section{Methodology}

\section{Data Collection}

Data for this study are from the 2000 National Survey on Recreation and the Environment (NSRE). ${ }^{7}$ The NSRE is a nationwide, random-digit-dialing telephone survey. We employ data from versions two, four, and six because only these versions included wilderness modules containing variables on wilderness use, attitudes, and perceptions addressing the questions listed above. These versions are representative of the entire country. The total sample size for version two is $5058 ; 5004$ for version four; and 5007 for version six.

\section{Wilderness Values Modules}

Ten questions/statements suitable for our research questions were developed for modules two, four, and six of the NSRE and are reported in Table 1. These items are based on three broad categories of natural resource and environmental benefits with consequent values that have been identified and discussed by social scientists, philosophers, resource managers, and stakeholders since the 1960s-active use values, passive use values, and instrinsic values (Krutilla 1967; Godfrey-Smith 1979; Randall and Stoll 1983; Hammond 1985; Rolston 1985; Haas, Herman, and Walsh 1986; Oelschlaeger 1991; Watson and Landres 1995; Noss 1996; Bergstrom and Loomis 1999; Morton 1999; Loomis and Richardson 2000).

Active use value items derive from direct contact or use of a natural resource or the environment. In Table 1, active use items include: (1) on-site, current use; (2) on-site, future use; (3) off-site, current use; (4) off-site, environmental quality; and (5) scientific/medicinal. Passive use values involve indirect use of a natural resource or the environment. In Table 1, passive use values include: (6) option; (7) intragenerational bequest; (8) intergenerational bequest; and (9) existence. The item 
TABLE 1 Wilderness Value Indicators

Use value indicator Wilderness value

Active use value indicator

1. Have you ever taken a trip to visit an area

On-site, current use value you knew for sure was one of the 625 designated wilderness areas?

2. Do you plan to visit a wilderness area within the next year?

3. I enjoy reading about and viewing pictures, videos, TV shows, and movies featuring wilderness areas.

4. Wilderness areas are important to protect because they contribute to better local, national, and global air and water quality.

5. Wilderness areas are important because they help to preserve plant and animal species that could have important scientific or human health values, such as new medicines.

Passive use value indicator

6. Even if you do not plan on visiting a wilderness area within the next year, would you want to visit one sometime in the future?

7. I enjoy knowing that other people are currently able to visit wilderness areas.

8. I enjoy knowing that future generations will be able to visit wilderness areas.

9. I support protecting wilderness just so they will always exist in their natural condition, even if no one were to ever visit or otherwise benefit from them.

Intrinsic value indicator

10. I believe the trees, wildlife, free flowing water, rock formations, and meadows that wilderness protect have value themselves whether or not humans benefit from them.

On-site, future use value

Off-site, current use value

Off-site, environmental quality value

Scientific/medical value

\author{
Option value \\ Intragenerational \\ bequest value \\ Intergenerational \\ bequest value \\ Existence value
}

Intrinsic value

indicating intrinsic value (10) in Table 1 refers to the value of wilderness areas and the biotic and abiotic components of wilderness areas unto themselves, independent of human active or passive use or benefits altogether. This is the only value indicator listed in Table 1 that is arguably not anthropocentric.

On-site, current use refers to values derived from visiting a wilderness area and would include on-site recreational, therapeutic, and spiritual values. On-site, future use refers to values derived from visiting a wilderness area in the future and would include future on-site recreational, therapeutic, and spiritual values. Off-site, current use refers to values derived from enjoying a wilderness area at a location away from the wilderness in a nonconsumptive manner. For example, a person may enjoy a wilderness 
area at home in a nonconsumptive manner by viewing videos or TV programs featuring wilderness areas or by looking at photographs of wilderness areas. Off-site environmental quality is the general value people place on clean air and water in the environment in which they live. Off-site environmental quality would include values placed on human health supported by clean air and water originating in a wilderness. Scientific/medicinal refers to the value of wilderness areas as "natural laboratories" and reservoirs of biodiversity that can support both scientific and medicinal values.

The option indicator refers to the value of maintaining the option to visit a wilderness in the future in addition to on-site future use value. For example, in terms of a money metric, option value is a type of "insurance premium" people would be willing to pay to ensure that wilderness will be available in the future to visit. Intragenerational bequest refers to values derived from knowing that other people currently living are enjoying wilderness. For example, a parent may derive enjoyment from the knowledge that a living child is able to visit wilderness. Intergenerational bequest refers to values derived from knowing that people in future generations yet to be born will be able to enjoy wilderness. For example, a person may derive enjoyment from the knowledge that a yet unborn grandchild or great-grandchild will be able to visit wilderness areas. Existence refers to the value people place on the cognitive knowledge that wilderness areas exist independent of current or future use by themselves or any other person.

The first two active indicators, on-site current use and on-site future use, were measured with indicator items having a nominal scale. In response to these questions, respondents could answer "yes," "no," "don't know," or "refused." The remaining three active use indicators were measured with a 5-point Likert-type scale including the following 5 ordinal delineations of agreement- "strongly agree," "agree," "neither agree nor disagree," "disagree," and "strongly disagree." For consistency of analysis, responses to these items were collapsed into dichotomous response categories (agree or not agree); that is, agree responses included "strongly agree" and "agree," while those not explicitly agreeing included "neither agree nor disagree," "disagree," and "strongly disagree." The first passive use indicator was nominally coded and analyzed as a yes or no dichotomous choice. The remaining passive use indicators were also dichotomously coded as the 5-point Likert scale items just given. In all cases, "don't know" and "refused" responses were coded missing.

\section{Logistic Analysis}

To better understand factors influencing one's response to the 10 questions/ statements pertaining to wilderness values listed earlier, multivariate logit methods were employed (Greene 2000, 811-837; Park and Kerr 1990). The logit model can be used to estimate the cumulative probability that an individual will respond yes (no) or agree (not agree) to each of the 10 items in Table 1 based on a set of explanatory variables. The dependent variable in this kind of nonlinear model is dichotomous and is coded as a one or zero. Logistic models have been recently employed in social science and recreation research to explore such issues as immigrant environmental behavior (Pfeffer and Stycos 2002), perceived constraints to outdoor recreation participation (Johnson, Bowker, and Cordell 2001a), and social acceptance of recreation user fees on public lands (Bowker, Cordell, and Johnson 1999).

The logistic model is generally specified as:

$$
\operatorname{Probability}(\text { yes })=1 /\left(1+e^{-\left(\alpha_{0}+\alpha_{1} X_{1}+\alpha_{2} X_{2}+\cdots\right)}\right)
$$


where $e$ is the base of the natural logarithm, $X$ terms are independent variables, and $\alpha$ terms are parameters of the distribution function. In this application, a logistic regression model is estimated for each of the 10 wilderness value items. To test for differences by immigration and race/ethnicity, we included the following independent variables: immigrant, ${ }^{8}$ Black, Latino, Asian, gender, age, education, urban residence, and acculturation. Gender, age, education, and urban residence are included as control variables. Three categorical variables are included to account for ethnicity/race-Black, Latino, and Asian. Native-born White is the base group or the group to which other race and ethnic groups are compared.

An additional categorical variable is included for immigrants. Categorical variables are also used for gender, postsecondary education level, and urban residence as defined by the U.S. Census. Respondents with postsecondary level education are coded 1 , and all others 0 . Urban is coded 1 for residence in a metropolitan county as defined by the U.S. census, and residence in nonmetropolitan counties is coded 0 . Age is measured in number of years.

We included a simple measure of acculturation in the models to account for the level of exposure to American society and culture. ${ }^{9}$ This variable allows us to control for differences in wilderness values among immigrants with different lengths of tenure in the United States. Our approach is similar to that used by Pfeffer and Stycos (2002) in studying immigrant environmental behaviors in New York. However, because our analysis includes both immigrants and nonimmigrants, we employed an interaction variable for acculturation-the product of the categorical immigrant variable mentioned earlier and the difference in years between the immigrant's arrival and the year the survey was administered.

A positive and significant sign on any of the estimated variable coefficients indicates that the variable increases the individual's probability of responding either yes or agree to a given value indicator. The converse is of course true for a negative coefficient sign. However, unlike linear regression, the coefficients cannot be interpreted as first derivatives, that is, the change in the dependent variable corresponding to a unit change in the independent variable. Because of the nonlinear nature of the function in Eq. (1), the marginal effects or first derivatives are themselves functions of the values of the independent variables and hence subject to variation, depending on the values of the independent variables at which they are computed.

\section{Results}

Ten logistic regression equations were estimated, one for each of the wilderness value indicators reported above using SAS. Table 2 reports results for the group of five items corresponding to the active use values listed in Table 1. Table 3 reports results for the five items corresponding to passive and intrinsic value items listed in Table 1. Both sets of results include regression coefficient estimates, odds ratios, sample means of independent variables, sample mean for the dependent variable, and measures of goodness of fit.

\section{Active Values}

\section{On-Site, Current Use}

On-site, current use value is represented by the question relating to previous wilderness visits (Table 1). The logistic regression allows testing whether the probability that an individual reported a trip to wilderness can be explained by 


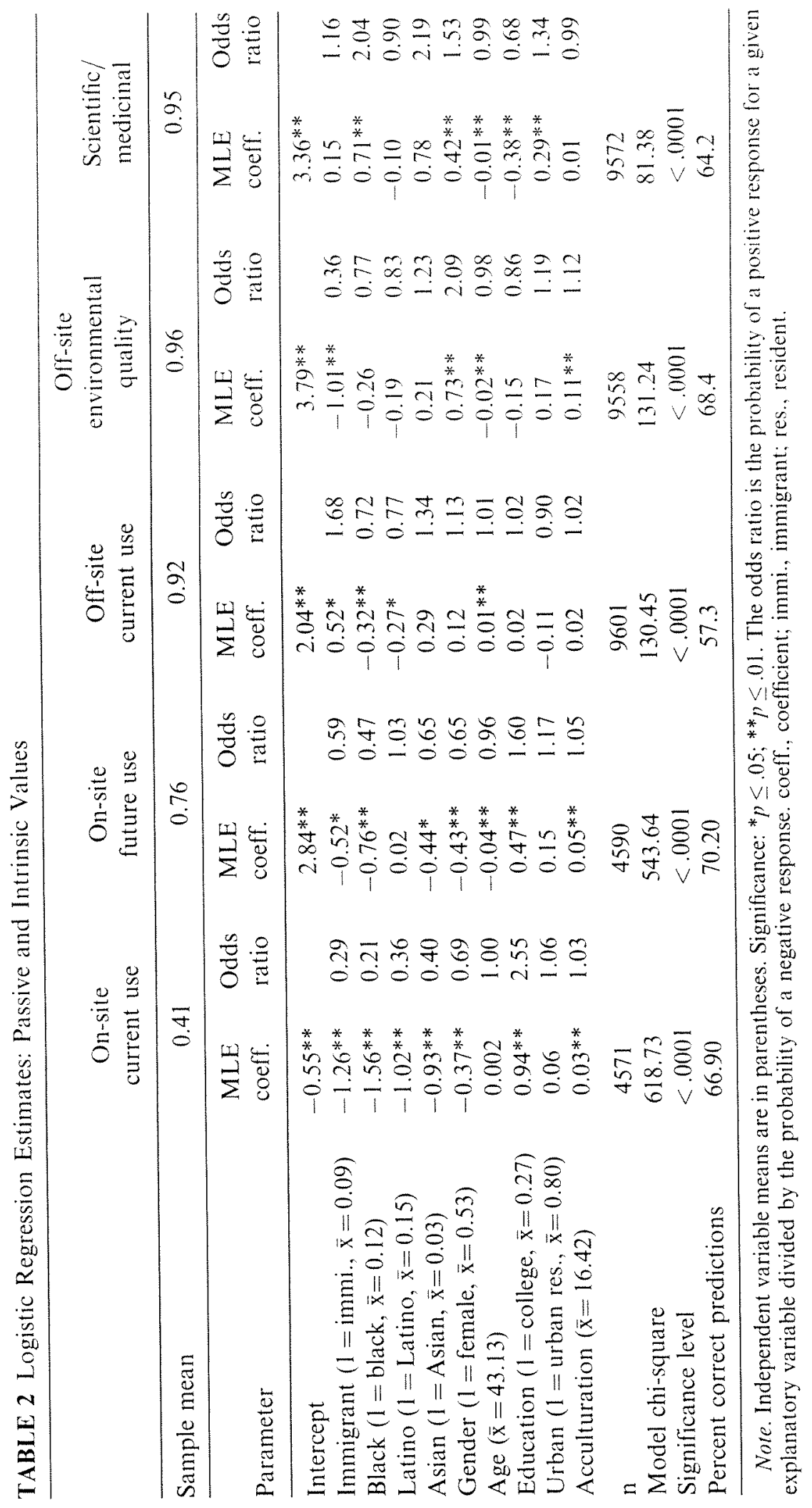




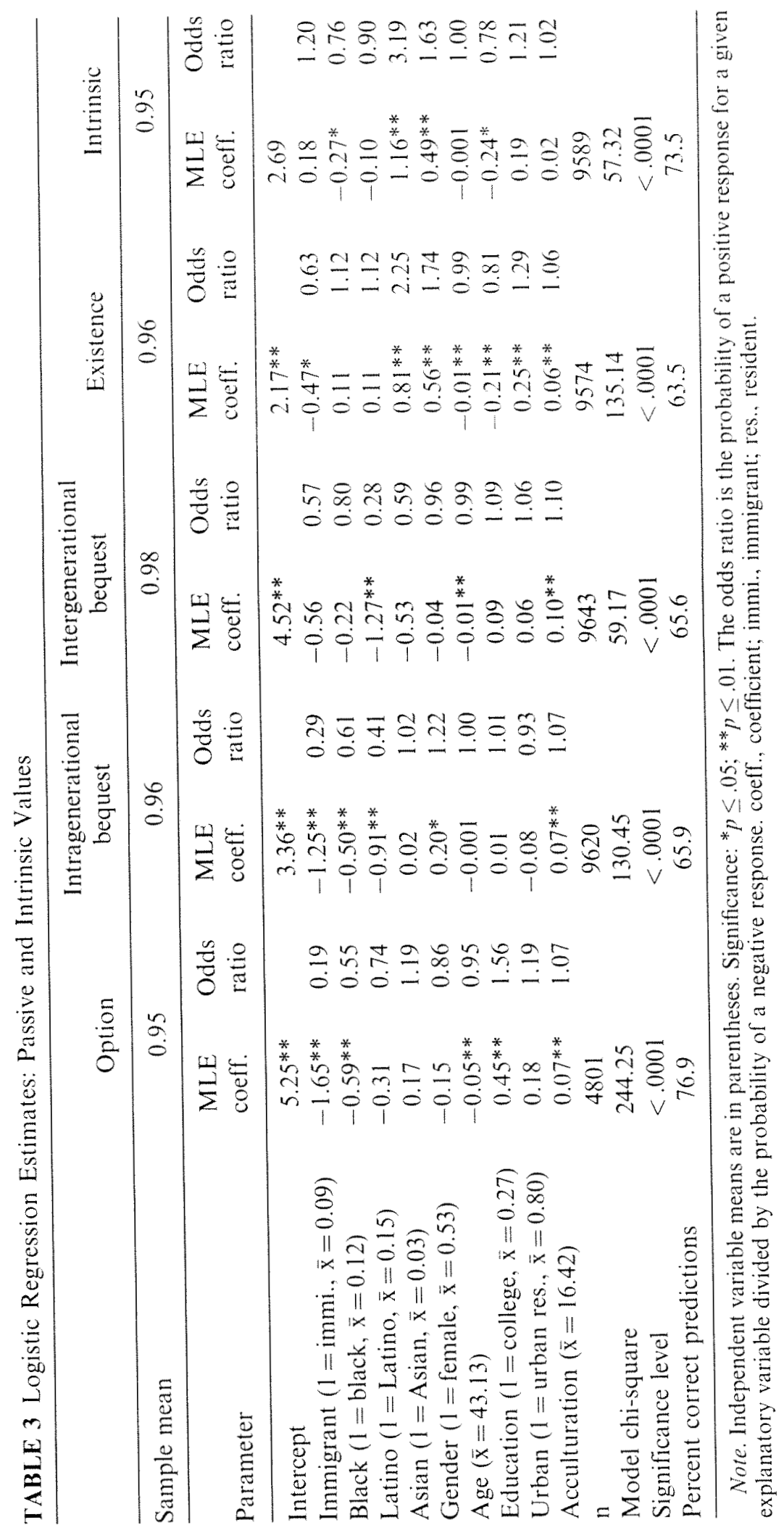


racial/ethnic or immigration status differences while controlling for the other socioeconomic factors. Table 2 shows logistic results for active use value items. Overall, $41 \%$ of respondents indicated that they had visited a federally designated wilderness area. Regression results show that when holding constant race/ethnicity, gender, age, education, urban residence, and acculturation, immigrants were statistically ( $p \leq .05$ ) less likely than native born respondents to visit wilderness, and hence would be less likely to have an on-site use value.

Compared to Whites, each of the race/ethnicity groupings, that is, Blacks, Latinos, and Asian Americans, were significantly less likely to say they had visited a wilderness. Also, women were less likely than men to visit, but people with postsecondary education were more likely than those without it to visit. It should be noted that acculturation, as represented by years living in America, had a positive effect on the probability that an immigrant had visited a wilderness. More acculturated immigrants were more likely to visit a wilderness, with other factors equal.

To assess differences in probability of visitation among immigrants and between immigrants and nonimmigrants, we calculated the probability of visitation for immigrants and nonimmigrants with various combinations of the other sociodemographic variables. The probability of a yes response on the dependent variable-that is, the probability the respondent has visited a wilderness--would be .38 for an urban-dwelling White, male immigrant, age 25 with postsecondary education, and an acculturation score of 10 (10 years in the United States). The probability of a foreign-born, Latino male with the same characteristics responding "yes" would be .18 , while a foreign-born Asian male with these characteristics would have a probability of having visited equaling 20 . The probability of visitation for a native-born, White male with the same characteristics would be .62. Further, the odds of a nativeborn, White male visiting would be more than 2.5 times higher than the odds of a foreign-born male visiting. With on-site use value, immigration status and ethnicity have rather large statistical and practical effects. ${ }^{10}$

\section{On-Site, Future Use}

For the second active use value indicator (plan to visit next year), immigrants were again less likely than native-born respondents to report a positive response. Blacks and Asians were also less likely than Whites to say they would visit within the next year, as were women. Older persons were less likely than younger respondents to plan a trip, and respondents with more than a high school education were more likely to plan a wilderness visit. Also, more acculturated immigrants were more likely to say they would plan a trip within the next year. Table 2 shows that $76 \%$ of the sample indicated a positive response for this item. The probability associated with a yes response for a 40-year-old Latina immigrant, urban dwelling, with no college education, and an acculturation score of 2, would be .66. The probability of a "yes" response for an Asian female immigrant with the same characteristics would be .55 , with 66 for a White female immigrant and .75 for a native-born White female.

\section{Off-Site, Current Use}

This value was assessed with the statement: "I enjoy reading about and viewing wilderness pictures, videos, TV shows, and movies" (Table 1). Immigrants and older respondents were more likely than others to indicate agreement for this value indicator. Blacks and Latinos were less likely than Whites to say they enjoyed this type of wilderness viewing. Although there were statistical differences for immigrants, Blacks, and Latinos, from a practical perspective there was only slight variation in 
the probability of an "agree" response for these groups. The differences are small and within a few percentage points. For instance, the probability of agreement to this item for a native-born Black male, age 28 , postsecondary level education, and urban residence would be .88 , with .90 for a White male, and .87 for a Latino male with similar sociodemographic characteristics. This kind of result is not uncommon when afforded the luxury of large sample size. At the sample mean, the odds of a Black person expressing agreement to this statement would be roughly $77 \%$ of the odds of White agreement.

\section{Off-Site Environmental Quality}

Immigrants and older respondents were less likely than others to indicate agreement for the statement: "Wilderness areas are important to protect because they contribute to better local, national, and global air and water quality." Women and more acculturated immigrants were more likely to agree to this item. To assess practical differences among immigrants, we calculated the probability of an "agree" response for immigrants with relatively high and low acculturation scores.

The probability of an "agree" response to this value item would be .98 for an immigrant, White male, 44 years old, no college, nonurban dwelling, having lived in the United States for 40 years. Race/ethnicity is not statistically significant, so a Latino immigrant with the same characteristics would have the same probability for a positive response. The probability decreases to .88 for both a White and Latino immigrant with similar characteristics who lived in the United States for 2 years. So, while immigration status adversely affects the probability of a positive response, the effect wears off with acculturation.

\section{Scientific/Medicinal Use}

Ninety-five percent of the sample responded positively to the value statement regarding wilderness as a habitat for plant and animal species for human health and medicine. Blacks, women, and urbanites were more likely to respond positively, compared to others. Older respondents and those with postsecondary education were less likely to respond positively. The odds of a Black person agreeing with this statement were twice as high as for Whites. Though Blacks were statistically different from Whites, practical differences between the two groups are minimal. The probability of a yes response for a Black female, age 40 , college education, and urban dwelling is virtually the same as that for a White female with these characteristics, .98 and .96, respectively. Again, while there is some statistical significance, the differences are quite small by practical standards, with no variable changing response probabilities more than a few percent from the sample mean of .95 .

\section{Passive Use Values}

\section{Option Value}

Table 3 contains analyses for passive use and intrinsic items associated with wilderness values. The first column shows results for option use value. For option value, immigrants, Blacks, and older respondents were less likely to say they would want to visit wilderness sometime in the future. Those with postsecondary education were more likely than those with less education to say they would make a future visit; and the longer immigrants had been in the country, the more likely they were to say they would like to make a future visit. The probability of wanting a future visit for a 50 -year-old male, Asian immigrant with postsecondary education, urban residence, 
and residence in the United States of 1 year would be .56. The probability increases to .74 for the same individual with 20 years of residence in the country. The probability would be 85 for a native-born, White male with a similar sociodemographic profile. The odds of a Black respondent desiring a future visit are about half the odds of a White respondent. Both race and immigrant status appear to play a major role here. However, acculturation has a relatively strong mitigating effect for immigrants.

\section{Intragenerational and Intergenerational Bequest Value}

Immigrants, Blacks, and Latinos were less likely to respond positively to the statement associated with this value. Females and more acculturated immigrants were more likely to respond positively. For intergenerational bequest value, again Latinos were less likely to give a positive response, as well as older individuals. More acculturated respondents were also more likely to answer positively. However, as with a number of the off-site use values already described, the practical differences from the overall sample mean probability are negligible.

\section{Wilderness Existing in Natural State}

U.S.-born Asians, women, urbanites, and more acculturated immigrants were more likely to say they supported wilderness protection so that wilderness would remain in its natural condition. Immigrants, older respondents, and those with postsecondary education were less likely to affirm this statement. The probability of an agree response for a U.S.-born Asian male, age 25, education beyond high school, living in an urban environment would be .94 . For a native-born White male, the probability decreases to .88 . While this difference is not dramatic, it suggests that Americans of European descent, or at least a faction within this group, are somewhat less likely to agree that wilderness should exist for its own sake than are other groups in the population. Asians were more than twice as likely as Whites to affirm this statement.

\section{Wilderness Has Intrinsic Worth}

U.S.-born Asians and women were more likely to indicate they believed the flora and fauna protected by wilderness held intrinsic value. Blacks and those with postsecondary education were less likely to agree with this statement. The probability of an agree response for a native-born Black male age 50 with postsecondary education and nonurban residence would be .89 . The probability would be .91 for a White male, and .97 for a native-born Asian male. Acculturation had no significant effect. Similar to the passive use value equations, there is very little practical difference among the variables explaining the probability of an agree response for this intrinsic indicator. However, the odds of an Asian respondent agreeing with this statement are about 3 times higher than for a White respondent, while a female is 1.63 times as likely to agree as a male.

\section{Discussion}

This research considered wilderness as social construction and whether values derived from it varied by immigrant or racial/ethnic minority status. Results show mixed support for the contention that Western conceptions of wilderness values are held primarily by native-born Whites. Immigrants were statistically less likely to express agreement for 6 of the 10 value indicators, findings that would confirm research question 1. Odds ratios on these variables ranged from .192 to .626 , suggesting appreciable differences between immigrants and natives. These ratios 
notwithstanding, practical differences were identified only for value items related to past or future visitation. Because of these minor differences in immigrant versus native probability for most of the value items, we cannot conclude that immigrants and natives perceive of or construct wilderness in culturally different terms.

We also compared native-born race/ethnic group responses for wilderness values. Of all ethnic groups compared, Black responses to the value items were least similar to those of Whites. Again, this was especially true for values relating to past and future use. This finding is consistent with prior research showing Blacks have less active engagement with wildland environments than Whites. The relative lack of Black visitation to wilderness may in part reflect the geographic distribution of Black population concentrations. Because the majority of Blacks live in urban areas in the Eastern portion of the country, they do not have easy access to the large wilderness preserves located in the West.

This argument notwithstanding, Johnson. Horan, and Pepper (1997) found that Blacks in several Southern counties having access to a federally designated wilderness were significantly less likely to visit than Whites. Lower visitation in this instance was related to the relatively negative perceptions Blacks held about wildlands. In terms of social constructionism, results for the present study suggest Blacks perceive of on-site wilderness use differently than Whites. However, Black and White differences related to off-site active values and passive use values were practically negligible. When we examined a wider range of wilderness values, not just those relating to direct use, we find evidence that Black and White responses do not differ dramatically.

Generally, U.S.-born Latino wilderness support was more like native-born White responses than Blacks. For Latinos, recognizable differences from Whites occurred for past use and for both intra- and intergenerational bequest value. But with respect to the bequest values, results do not suggest that U.S.-born Latinos see wilderness much differently than Whites across most dimensions. It is worth noting that for values representing future use and optional use, Latinos showed no statistical difference from Whites. This could imply that the relative growth in the U.S. Latino population will eventually result in increased wilderness visitation. This could be compounded by the positive effect of the acculturation variable in most equations.

Asians were the only ethnic minority to be more likely than Whites to respond positively to items relating to existence and intrinsic values. Because both these values represent more biocentric views, these results provide some support for the contention that Asian Americans may hold more holistic, non-human-centered views of wild nature. Like Blacks and Latinos, Asians were also less likely to have visited wilderness than Whites. However, like Latinos, the expectation and value for eventual future use was insignificantly different than Whites.

The present study is an attempt to incorporate the views of more peripheral groups (immigrants, Blacks, Latinos, Asians) into a discussion of wilderness valuation and ultimately wilderness policy. National Wilderness Preservation System (NWPS) critics charge that wilderness is the concern of a privileged group of Americans, and the values it generates are captured primarily by middle to upper income Whites (DeLuca 1999; Taylor 2000). Again, to some extent our findings support this charge as far as past or near-term on-site visitation is concerned. However, insofar as values derived from off-site use and passive use values of wilderness are concerned, there appears to be little practical difference between native-born Whites and the other native-born racial/ethnic groups in this study. The 
same can be said between native-born Americans and immigrants, especially when one considers the mitigating effect of acculturation.

As stated, the most notable differences between Whites and other groups relate to visitation. These findings suggest a need for further research exploring factors that might contribute to use differences. The present study is limited to national household survey data that provide relatively course indications of valuation categories. Respondents indicated values indirectly via a set of researcherdefined questions/statements. However, respondents may value wilderness in terms considerably more complex than our indicator items can discern. More in-depth techniques employing qualitative methods could be used to understand better the underlying reasons why immigrants and minorities appear less willing to visit wilderness.

A number of economic studies have shown that even among the not-so-diverse users of wilderness, the largest portion of personal economic values of wilderness areas is attributed to off-site use and passive use benefits. Our results suggest something similar for both minorities and immigrants. The continuance of the NWPS will ultimately depend to a great extent on the popular political support of all voting Americans and the varied perspectives they hold about wilderness. If support for passive use values and future use values are correctly assessed by our study, then political support for wilderness may not diminish appreciably in the future as America becomes more diverse.

\section{Notes}

1. This estimate is based on the middle series U.S. Census estimates. The lowest series projects a seven percent increase, and the highest series a $200 \%$ increase.

2. Willers (2001), on the other hand, critiques the social constructionist, postmodern challenge to wilderness as an obdurate reality against which less ecological land use options may be compared. He maintains that from a biological point of view, wilderness is an "essential" entity that "does have a reality and an identity distinct from the ideas any given culture might have about it." See also Soulé (1995).

3. For instance, Latinos and Native Americans in the Southwest, Asian Americans in the Pacific West, and Southern Blacks have all been divested of land via unscrupulous means. It has been theorized that this history of exploitation associated with the land may have contributed to a wildland aversion among African Americans (Johnson 1998).

4. Inglehart's $(1990 ; 1995)$ postmaterialist thesis, however, does not consider class variation within emerging industrial societies. Even if postmaterial status is the most influential factor determining environmental concern, there are still important class differences both within any given cultural group and also between different groups. More recent immigrants from Mexico, for instance, are more likely to be working-class "labor immigrants" while Asian immigrants from Korea and China are more likely to be "human capital immigrants" who possess higher educational, technical, or entrepreneurial skills than the former (Alba and Nee 1997; see also Portes and Rumbaut 1996; Yang 1999). Because of wealth and educational differences among immigrant groups, there may be differential exposure to Western intellectual traditions before immigrants arrive in the United States. Some immigrants may have more knowledge of American attitudes about wilderness preservation and valuation than others.

5. Nonuse values attribute worth to the mere existence of wilderness or to the knowledge that wilderness protects wildlife and wild places. These are contrasted with use values, which 
assign importance to wilderness as a source that contributes more directly to human satisfaction or gratification such as recreation or tourism.

6. Regardless of race of ethnic background.

7. For more information on the NSRE, contact Gary Green at ggreen a fs.fed.us.

8. Fifty percent of immigrants have been in the United States since 1988. The earliest immigration year reported was 1925. The immigrant sample is 55\% Hispanic (Latino) and $14 \%$ Asian origin.

9. We acknowledge an anonymous reviewer for suggesting that we include an acculturation variable. Ours is an elementary measure of acculturation. Acculturation is a complex process that involves language preference and specific lifestyle variables that were not included in the NSRE. However, as indicated in the text, length of residence has been used in recently published work dealing with environmental practices.

10. These probabilities can be estimated by programming the estimates in Tables 2 and 3 into Eq. (I) using any standard spreadsheet program.

\section{References}

Alba, R. and V. Nee. 1997. Rethinking assimilation theory for a new era of immigration. Int. Migration Rev. 31(4):826-874.

Altieri, M. A. and O. Masera. 1993. Sustainable rural development in Latin America: Building from the bottom up. Ecol. Econ. 7:93-121.

Bannock, G., R. E. Baxter, and E. Davis. 1998. Dictionary of economics. New York: John Wiley \& Sons.

Barker, O. 2001. The Asianization of America. USA Today 22 March, pp. 1A-2A.

Beck, R. 1997. Immigration-fueled U.S. population growth is "spoiler" in economic, social and environmental efforts. Population Environ. J. Interdiscip. Stud. 18(5):483-487.

Bergstrom, J. C. and J. B. Loomis. 1999. Economic dimensions of ecosystem management. In Integrating social sciences with ecosystem management, ed. H. K. Cordell and J.C. Bergstrom, 181-193. Champaign, IL: Sagamore.

Bowker, J. M., H. K. Cordell, and C. Y. Johnson. 1999. User fees for recreation services on public lands: A National assessment. J. Park Recreation Admin. 17(3):1-14.

Callicott, J. B. 1994/1995. A critique of and an alternative to the wilderness idea. Wild Earth Winter:54-59.

Callicott, J. B. and M. P. Nelson. 1998. The great new wilderness debate. Athens: University of Georgia Press.

Castles, S. C. and M. J. Miller. 1998. The age of migration: International population movements in the modern world, 2nd ed. New York: Guilford Press.

Cordell, H. K., G. T. Green, and C. J. Betz. 2002. Recreation and the environment as cultural dimensions in contemporary American society. Leisure Sci. 24(1):13-41.

Cordell, H. K. and J. Stokes. 2000. The social value of wilderness: A Forest Service perspective. Int. J. Wild. 6(2):23-24.

Cordell, H. K., M. A. Tarrant, and G. T. Green. 2003. Is the public viewpoint of wilderness shifting? Int. J. Wild. 9(2):27-32.

Cordell, H. K., M. A. Tarrant, B. L. McDonald, and J. C. Bergstrom. 1998. How the public views wilderness. Int. J. Wild. 4(3):28-31.

Cronon, W. 1996. The trouble with wilderness or, getting back to the wrong nature. Environ. Hist. 1(1):7-28.

DeLuca, K. 1999. In the shadow of whiteness. In Whiteness: The construction of social identity, ed. T. K. Nakayama and J. N. Martin, 217-246. Thousand Oaks, CA: Sage.

Ehrlich, P. R. and A. H. Ehrlich. 1990. The population explosion. New York: Simon and Schuster.

Godfrey-Smith, W. 1979. The value of wilderness. Environ. Ethics 1(4):309-319. 
Gramann. I. H. 1996. Ethnicity, race, and outdoor recreation: A revien of trends, policy, and research. Miscellaneous paper R-96-1. March. U.S. Army Corps of Engineers. Washington, DC.

Greene, W. H. 2000. Econometric analysis, 4th ed. Englewood Cliffs, NJ: Prentice Hall.

Greider, T. and L. Garkovich. 1994. Landscapes: The social construction of nature and the environment. Rural Sociol. 59(1):1-24.

Guha, R. 1989. Radical American environmentalism and wilderness preservation: A Third World critique. Environ. Ethics 11(1):71-83.

Haas, G. E. E. Hermann, and R. Walsh. 1986. Wilderness values. Natural Areas $J .6(2): 37-43$. Hammond, J. L. 1985. Wilderness and heritage values. Environ. Ethics 7:165-170.

Hunter, L. M. 2000. A comparison of the environmental attitudes, concern, and behaviors of native-born and foreign-born U.S residents. Population Environ. J. Interdiscip. Stud. $21(6): 565-580$.

Inglehart. R. 1990. Culiure shift in advanced industrial society. Princeton. NI: Princeton University Press.

Inglehart, R. 1995. Public support for environmental protection: Objective problems and subjective values in 43 societies. PS: Polit. Sci. Politics March:57-72.

Johnson, C. Y. 1998. A Consideration of collective memory in African American attachment to wildland recreation places. Hum. Ecol. Rev. 5(1):5-15.

Johnson, C. Y., J. M. Bowker, and H. K. Cordell, 2001a. Outdoor recreation constraints: An Examination of race, gender, and rural dwelling. South. Rural Sociol. 17(1):111-133.

Johnson, C. Y., J. M. Bowker, H. K. Cordell, and C. J. Betz. 2000. Wildeness awareness and participation: A comparison across race and ethnicity. Presentation at the Wilderness Values Workshop, Washington, DC, July.

Johnson, C. Y., J. M. Bowker, H. K. Cordell, C. J. Betz, and G. Green. 2001b. Wilderness constraints by race and ethnicity. Presentation at the Southern Forest Science Conference, Atlanta, GA, November.

Johnson, C. Y., P. M. Horan, and W. Pepper. 1997. Race, rural residence, and wildland meaning: Examining the influence of sociocultural meaning. Rural Sociol. 62:89-110.

Krutilla, J. V. 1967. Conservation reconsidered. Am. Econ. Rev. 57:777-786.

Loomis, J. B. and R. Richardson. 2000. Economic values of protecting roadless areas in the United States. Washington, DC: The Wilderness Society.

Lucas, R. C. 1989. A Look at wilderness use and users in transition. Natural Resources $J$. 29:41-55.

Lynch, B. D. 1993. The garden and the sea: U.S. Latino environmental discourses and mainstream environmentalism. Social Problems 40(1):108-123.

Morton, P. 1999. The economic benefits of wilderness: Theory and practice. Denver Univ. Law Rev. $76(2): 465-518$.

Nash, R. 1982. The international perspective. In The great new wilderness debate, ed. J. B. Callicott and M. P. Nelson, 207-216. Athens: University of Georgia Press.

Noss, R. 1996. Soul of the wilderness: Biodiversity, ecological integrity and wilderness. Int. J. Wild. 2(2):3-8.

Oelschlaeger, M. 1991. The idea of wilderness: From prehistory to the age of ecology. New Haven, CT: Yale University Press.

Park, K. H. and P. M. Kerr. 1990. Determinants of academic performance: A Multinomial logit approach. J. Econ. Educ. 19:101-111.

Parajuli, P. 2001. How can four trees make a jungle? In The world and the wild: Expanding wilderness beyond its American roots, ed. D. Rothenberg and M. Ulvaeus, 3-20. Tucson: University of Arizona Press.

Pfeffer, M. J. and J. M. Stycos. 2002. Immigrant environmental behaviors in New York City. Social Sci. $Q .83(1): 6481$.

Pimentel, D., M. Giampietro, and S. G. F. Bukkens. 1998. An optimum population for North and Latin America. Population Environ. J. Interdiscip. Stud. 20(2):125-148. 
Portes, A. and R. Rumbaut. 1996. Immigrant America: A portrait, 2nd ed. Berkeley: University of California Press.

Randall. A. and J. R. Stoll. 1983. Existence value in a total economic value framework. In Managing air quality and scenic resources at national parks and wilderness areas, ed. R. Rowe and $\mathrm{L}$. Chestnut. Boulder, CO: Westview Press.

Roggenbuck, J. W. 1988. Wilderness use and user characteristics: Ending some misconceptions. Western Wildlands Fall:8-14.

Rolston. H. 1985. Valuing wildlands. Environ. Ethics 7(1):23-48.

Schelhas, J. 2002. Race, ethnicity, and natural resources in the United States: A review. Nat. Resources J. 42(4):723-763.

Schönfeld, M. 2000. Population growth and the preservation of wilderness. J. Social Philos. $31: 414-428$

Soulé, M. E. 1995. The social siege of nature. In Reimenting nature?, ed. M. E. Soule and G. Lease, 137-170. Washington, DC: Island Press.

Southgate, D. and H. L. Clark. 1993. Can conservation projects save biodiversity in South America? Ambio 22(2-3):163-166.

Stankey, G. H. 2000. Future trends in society and technology: Implications for wilderness research and management. USDA Forest Service Proceedings RMRS-P-15, vol. 1, 10-23. Fort Collins: Rocky Mountain Research Station.

Taylor, D. E. 2000. The rise of the environmental justice paradigm: Injustice framing and the social construction of environmental discourses. Am. Behav. Sci. 43(4):508-580.

U.S. Department of Commerce, Bureau of the Census. 1996. Current population reports: Population projections of the United States by age, sex, race, and Hispanic origin: 19952050: p25-1130, 1-31. Available at http://www.census.gov/prod/1/pop/p25-1130.

Walker, G. J. and K. J. Kiecolt. 1995. Social class and wilderness use. Leisure Sci. 17:295-308.

Washburne, R. F. 1978. Black underpartcipation in wildland recreation: Alternative explanations. Leisure Sci. 1(2):175-189.

Watson, A. and P. Landres. 1999. Changing wilderness values. In Outdoor recreation in American life: A national assessment of demand and supply trends, ed. H. K. Cordell, 384 388. Champaign, IL: Sagamore.

Watson, A. E., D. R. Williams, J. W. Roggenbuck, and J. J. Daigle. 1992. Visitor characteristics and preferences for three national forest wildernesses in the south. USDA Forest, Ogden, UT Service, Intermountain Research Station, Research Paper INT-455.

Western. D. 2001. In the dust of Kilimanjaro. In The world and the wild: Expanding wilderness beyond its American roots, ed. D. Rothenberg and M. Ulvaeus, 65-79. Tucson: University of Arizona Press.

Willers, B. 2001. The postmodern attack on wilderness. Nat. Areas J. 21(3):259-265.

Williams, D. 2000. Personal and social meanings of wilderness: Constructing and contesting places in a global village. In Personal, societal, and ecological values of wilderness: Sixth norld wilderness congress proceedings on research, management, and allocation, Vol II. comp. A. E. Watson, G. H. Aplet, and J. C. Hendee, 77-82. USDA Forest Service Proceedings, RMRS-P-14, Fort Collins, CO.

Williams, D. R., M. E. Patterson, J. E. Roggenbuck, and A. E. Watson. 1992. Beyond the commodity metaphor: Examining emotional and symbolic attachment to place. Leisure Sci. 14:29-46.

Winter, P. 1996. San Gorgonio Wilderness visitor survey, summer and fall 1994. USDA Forest Service, Pacific Southwest Station. Unpublished research report.

Yang, P. Q. 1999. Quality of post-1965 Asian immigrants. Population Environ. J. Interdiscip. Stud. 20(6):527-544. 